\title{
Follow-up care of young childhood cancer survivors: attendance and parental involvement
}

Vetsch Janine (MSc) ${ }^{1}$, Rueegg S. Corina (PhD) ${ }^{1}$, Mader Luzius (MSc) $)^{1}$, Bergstraesser Eva (MD) ${ }^{2}$, Rischewski Johannes (MD) ${ }^{3}$, Kuehni Claudia (MD, MSc) ${ }^{4}$, Michel Gisela (PhD) $)^{1,4}$

For the Swiss Paediatric Oncology Group*

${ }^{1}$ Department of Health Sciences \& Health Policy, University of Lucerne, Frohburgstrasse 3, 6002 Lucerne, Switzerland ${ }^{2}$ Department of Oncology/Hematology, University Children's Hospital Zurich, Steinwiesstrasse 75, 8032 Zurich, Switzerland ${ }^{3}$ Department of Oncology/Hematology, Children’s Hospital, Cantonal Hospital Lucerne, 6000 Lucerne, Switzerland ${ }^{4}$ Institute of Social and Preventive Medicine, University of Bern, Finkenhubelweg 11, 3012 Bern, Switzerland

*Swiss Paediatric Oncology Group (SPOG) Scientific Committee: Prof. Dr. med. R. Ammann, Bern; Dr. med. R. Angst, Aarau; Prof. Dr. med. M. Ansari, Geneva; PD Dr. med. M. Beck Popovic, Lausanne; Dr. med. P. Brazzola, Bellinzona; Dr. med. J. Greiner, St. Gallen; Prof. Dr. med. M. Grotzer, Zurich; Dr. med. H. Hengartner, St. Gallen; Prof. Dr. med. T. Kuehne, Basel; Bern; Prof. Dr. med. K. Leibundgut, Bern; Prof. Dr. med. F. Niggli, Zurich; Prof. Dr. med. N. von der Weid, Basel.

\section{Corresponding author:}

Gisela Michel, Department of Health Sciences and Health Policy, University of Lucerne

Frohburgstrasse 3, 6002 Luzern, Switzerland

Phone:+41 41 2295955, Fax: +41 41 2295635, E-mail: gisela.michel@unilu.ch

Acknowledgements: We thank all parents of survivors for participating in our survey, the study team of the Swiss Childhood Cancer Survivor Study (Erika Brantschen Berclaz, Micòl Gianinazzi, Julia Koch, Fabienne Liechti), the data managers of the Swiss Paediatric Oncology Group (Claudia Anderegg, Nadine Beusch, Rosa-Emma Garcia, Franziska Hochreutener, Friedgard Julmy, Nadine Lanz, Heike Markiewicz, Genevieve Perrenoud, Annette Reinberger, Renate Siegenthaler, Verena Stahel, and Eva Maria Tinner), and the team of the Swiss Childhood Cancer Registry (Vera Mitter, Elisabeth Kiraly, Marlen Spring, Christina Krenger, Priska Wölfli).

Financial support: This work was supported by the Swiss National Science Foundation (100019_153268/1; Ambizione grant PZ00P3_121682/1 and PZ00P3-141722 to GM). The Swiss Childhood Cancer Survivor Study was funded by the Swiss Cancer League (KLS-2215-02-2008, KFS-02631-08-2010, KLS-02783-02-2011). The work of the Swiss Childhood Cancer Registry is supported by the Swiss Paediatric Oncology Group (www.spog.ch), Schweizerische Konferenz der kantonalen

Gesundheitsdirektorinnen und -direktoren (www.gdk-cds.ch), Swiss Cancer Research (www.krebsforschung.ch), Kinderkrebshilfe Schweiz (www.kinderkrebshilfe.ch), Ernst-Göhner Stiftung, Stiftung Domarena and National Institute of Cancer Epidemiology and Registration (www.nicer.ch).

\section{Citation:}

Vetsch, Janine; Rüegg, Corina Silvia; Mader, Luzius; Bergstraesser, Eva; Rischewski, Johannes; Kuehni, Claudia E; Michel, Gisela (2016). Follow-up care of young childhood cancer survivors: attendance and parental involvement. Supportive care in cancer, 24(7), S. 3127-3138. Springer 10.1007/s00520-016-3121-6 


\title{
Follow-up care of young childhood cancer survivors: attendance and parental involvement
}

\author{
Vetsch Janine (MSc) ${ }^{1}$, Rueegg S. Corina (PhD) ${ }^{1}$, Mader Luzius (MSc) ${ }^{1}$, Bergstraesser Eva (MD) ${ }^{2}$, Rischewski Johannes (MD) ${ }^{3}$, \\ Kuehni Claudia (MD, MSc) ${ }^{4}$, Michel Gisela $(\mathrm{PhD})^{1,4}$ \\ For the Swiss Paediatric Oncology Group*
}

\begin{abstract}
Purpose: Despite recommendations, only a proportion of long-term childhood cancer survivors attend follow-up care. We aimed to 1) describe follow-up attendance of young survivors aged 11-17 years; 2) describe parental involvement in follow-up, and 3) investigate predictors of follow-up attendance and parental involvement.

Methods: As part of the Swiss Childhood Cancer Survivor Study a follow-up questionnaire was sent to parents of childhood cancer survivors aged 11-17 years. We assessed follow-up attendance of the child, parents' involvement in follow-up, illness perception (Brief IPQ) and socio-demographic data. Clinical data was available from the Swiss Childhood Cancer Registry.

Results: Of 309 eligible parents 189 responded (67\%; mean time since diagnosis 11.3 years, range 6.8-17.2) and 75\% $(\mathrm{n}=141)$ reported that their child still attended follow-up. Of these, $83 \%(\mathrm{n}=117)$ reported $\geq 1$ visit per year and $17 \%$ $(n=23)<1$ visit every year. Most survivors saw pediatric oncologists ( $n=111 ; 79 \%$ of 141 ), followed by endocrinologists $(n=24,17 \%)$ and general practitioners $(n=22,16 \%)$. Most parents (92\%) reported being involved in follow-up $(\mathrm{n}=130)$. In multivariable and Cox regression analyses, longer time since diagnosis $(\mathrm{p}=0.025)$ and lower perceived treatment control (assessed by IPQ4: how much parents thought follow-up can help with late effects; $\mathrm{p}=0.009)$ were associated with non-attendance. Higher perceived treatment control was the only factor associated $(\mathrm{p}=0.041)$ with parental involvement.

Conclusion: Educating survivors and their parents on the importance and effectiveness of follow-up care might increase attendance in the longer term.
\end{abstract}

Key words (4-6): parents of childhood cancer survivors; pediatric oncology; follow-up care; cohort study; questionnaire survey; young childhood cancer survivors

\section{INTRODUCTION}

Risk-based follow-up care is important for childhood cancer survivors to identify and treat late effects [1-3]. Due to their high risk for medical late effects such as cardiovascular or neurological complications and second malignancies, guidelines have been developed to provide recommendations for risk-stratified longterm follow-up care [4-6]. These guidelines aimed to increase awareness of potential late effects, standardize follow-up across different medical specialists involved and increase follow-up attendance of survivors. Despite these recommendations only around $20-40 \%$ of adolescent and adult long-term survivors are in longterm follow-up in Switzerland [7-9]. Factors associated with attendance were: younger age at study, older age at diagnosis and higher risk of treatment-related late effects [7]. Only one study from the US reported that young survivors between completion of treatment and 5 years post-diagnosis were less likely to attend followup if being male, having a brain tumor, longer time off treatment, and greater distance from hospital [10].

Parents play an important role in follow-up care of young survivors and are expected to be actively involved [11]. With children they are the caretakers and provide practical support, such as transportation to appointments. In addition, adult childhood cancer survivors are frequently accompanied by their mothers to follow-up visits. Reasons for this included concerns for health and well-being of their child, parental duty, personal interest and companionship [12]. Two studies showed that parents accompanied young adult survivors to follow-up care because of concerns about their child's overall health and cancer recurrence [13, 14]. We assume that parental involvement is influenced by their emotional state and how much they are affected by the illness. Follow-up care might provide an opportunity for parents to discuss their concerns and worries. However, there are no studies investigating follow-up attendance and parental involvement in follow-up care of young survivors of childhood cancer (aged below18 years) with regards to the opportunity of education to emphasize the importance of follow-up care.

We aimed to 1) describe current follow-up care of young childhood cancer survivors (aged 11-17 years) in Switzerland, including specialists visited and reasons for non-attendance; 2) describe parental involvement in follow-up care, and 3) investigate associations of follow-up attendance and parental involvement with clinical characteristics of the child, socio-demographic characteristics of parents and parents' illness perception.

\section{METHODS}

\section{Sample and procedure}

The Swiss Childhood Cancer Registry (SCCR) is a population-based registry including all cancer patients younger than 21 years and Swiss residents at diagnosis, who were diagnosed with leukemia, lymphoma, central nervous system (CNS) tumors, malignant solid tumors or Langerhans cell histiocytosis [15, 16]. The Swiss Childhood Cancer Survivor Study (SCCSS) is an ongoing, nationwide, long-term survey which includes 
a baseline questionnaire (years 2007-2012) and a subsequent follow-up questionnaire (years 2010-2012). The baseline questionnaire included all patients registered in the SCCR who were diagnosed between 1976-2005, aged below 16 years and having survived for at least 5 years [17]. Parents of survivors aged $\leq 15$ years completed the questionnaire for their children, whereas survivors $16+$ years completed their own questionnaire. They received an initial information letter about the study from their former treating hospital. Ten days later they received a questionnaire with a prepaid return envelope. Non-responders were sent another questionnaire 4-6 weeks later. If they did not reply they were personally contacted by phone.

The follow-up survey was performed approximately 1-3 years later. To collect the data reported in this paper a questionnaire was sent to all parents who had responded to the baseline questionnaire and whose child was aged 11-17 years at time of study ( $n=306$; Supplemental Figure 1). The parent who had completed the baseline questionnaire was contacted again and received the questionnaire with a prepaid return envelope. Those who did not reply within two months, received a reminder with another questionnaire and prepaid return envelope. Questionnaires were available in German and French. Ethics approval was provided through the general cancer registry permission of the SCCR (The Swiss Federal Commission of Experts for Professional Secrecy in Medical Research). Additionally, we received a non-obstat statement from the ethics committee of the canton of Bern declaring that the ethics committee did not object to the conduct of the study. Participants gave implied informed consent for the study by returning the completed questionnaire.

\section{Measurements}

Outcomes assessed in the follow-up questionnaire Follow-up care attendance

In Switzerland, childhood cancer survivors are regularly followed-up by their pediatric oncologist for 10 years after diagnosis often into their early twenties, and are then usually discharged to a general practitioner (GP) or medical oncologist. Others may continue follow-up with their pediatric oncologist longer into adulthood. If discharged from pediatric oncology, further follow-up is poorly standardized. In younger survivors a parent usually attends follow-up appointments together with their child. However, as part of transition, most clinicians will have private appointments with the survivor only. We asked parents if their child still attended follow-up: 1) 'yes, my child still attends regular follow-up appointments'; 2) 'yes, my child still has irregular follow-up appointments'; 3) 'no, regular follow-up is completed, but my child goes to the doctor for any cancer-associated complications; 4) 'no, regular follow-up is completed and my child has not seen the doctor for a while'. For the analysis a binary variable was created: attenders (responses 1 or 2) and non-attenders (responses 3 or 4).
Parents of attenders were asked how frequently their child attends follow-up care (several times a year; once a year; every 2-3 years; every 4-5 years) and to indicate the health care provider on a list including: general practitioner, pediatric oncologist, adult oncologist, radiotherapist, gynecologist, psychologist, endocrinologist, and any other healthcare providers.

Parents of survivors only seeing a doctor for cancerassociated complications were asked which doctor they would visit in case of problems. The same list of specialists as described above was provided. Parents of survivors who had stopped attending follow-up seeing only a GP could give reasons why: 'child was officially discharged ', 'child lives too far from a follow-up possibility', 'child is afraid that late effects could be detected', 'child doesn't want to visit a children's hospital', 'child thinks follow-up is unimportant'. Parents of non-attenders were asked the year of followup completion.

\section{Parental involvement}

Parents were asked whether they are currently involved in follow-up care of their child: (yes/no).

\section{Explanatory variables assessed by questionnaire}

We assessed parents' sex, age at study, migration background, language region, parents' education and employment status. Parents' age at study was divided in two categories $\leq 45$ years and $>45$ years. Parents were classified as having a migration background if they were not Swiss citizens by birth or not born in Switzerland. Language region was divided into German and French. Parents' education was divided into three categories: primary (compulsory schooling only); secondary (including vocational training, teachers, technical, commercial schools etc.); tertiary (including university) [18]. Employment status was coded as employed (yes/no).

We also included an adapted version of the Brief Illness Perception Questionnaire (Brief IPQ) [19]. The Brief IPQ is a theoretically derived instrument providing information about components underlying the cognitive representation of the illness. We adapted the questions to parents of childhood cancer survivors as proposed in the manual of the IPQ. We wanted to assess how the former cancer disease and possible late effects still affect parents. Parents could express their accordance on an 11-point scale ( $0=$ absolutely not, $10=$ absolutely) for the following items: cognitive illness representations: consequences (how much do the consequences of your child's illness affect your life?), timeline (how long do you think the consequences of the child's illness will continue?), personal control (how much control do you feel you have over the consequences of your child's illness?), treatment control (how much do you think follow-up care can help with late effects of your child?), and identity (how often does your child experience symptoms from the illness consequences?); emotional representations: concerns (how concerned are you about your child's illness?) and emotions (how much do the child's illness consequences affect you 
emotionally?); illness comprehensibility (how well do you feel you understand your child's illness consequences?).

From the baseline questionnaire of the SCCSS we extracted information about parent-reported late effects on the survivor (yes/no) [17].

\section{Clinical variables extracted from the Swiss Childhood Cancer Registry}

We extracted medical information on diagnosis and treatment of the child from the SCCR: cancer diagnosis, cancer treatment, type of treating hospital, age at study, time since diagnosis and relapse. We classified diagnosis according to the International Classification of Childhood Cancer (third edition) [20]. For analyses we grouped diagnoses into six major categories: leukemia, lymphoma, CNS tumors, neuroblastoma, bone/soft tissue sarcoma (STS) and other tumors. Treatment was coded as: surgery only, chemotherapy (without radiotherapy but may have had surgery), radiotherapy (may have had surgery and/or chemotherapy) and stem cell transplantation (SCT; may have had surgery and/or chemotherapy and/or radiotherapy). The type of treating hospital was divided into university hospital and regional hospital. Age at study was divided into: $<14$ years, $14-15$ years and $>15$ years. Time since diagnosis was divided into: 5-9 years, 10-14 years and 15-17 years. Relapse was coded yes or no.

\section{Analyses}

All analyses were performed using Stata 13.1. We used descriptive statistics, chi-square statistics and t-tests to describe the study population, current follow-up care and parental involvement. We used univariable and multivariable logistic regression models to analyze associations of clinical characteristics, sociodemographic characteristics and illness perception with follow-up attendance and parental involvement. The variables age at study, child's age at study and time since diagnosis were centered around the mean for the regression analyses. In the multivariable model we included all variables that were statistically significant at $\mathrm{p}<0.05$ in the univariable model. We used likelihood ratio tests to calculate p-values in the multivariable regression models. For the cumulative follow-up attendance analyses, follow-up time was calculated from date of diagnosis until date of follow-up completion or date of questionnaire completion if survivor was still in follow-up. Cox proportional hazards regression model was used to calculate cumulative follow-up attendance over time since diagnosis adjusted for age at study and time since diagnosis, and shown in a Kaplan-Meier estimation curve.

\section{RESULTS}

Of the 306 eligible parents, we traced and contacted 284 (Supplemental Figure 2). Of those, 189 (67\%) responded. The mean age of the parents was 46.1 years (SD 4.8, range 33.5-59.5 years),

mean time since diagnosis 11.3 years (SD 2.5, range 6.8-17.2) and mean age of the child at study completion was 14.7 years (SD 1.8, range 10.7-18.0 years; Table 1). Most children were

diagnosed with leukemia (39.2\%), followed by CNS tumors (18.0\%) and lymphomas (8.5\%). Participating and non-participating parents were similar regarding language region of Switzerland, cancer type, treatment received, type of treating hospital, child's age at diagnosis, time since diagnosis, relapse status and parent-reported late effects.

\section{Follow-up care attendance}

Most parents ( $n=141,74.6 \%$ ) reported that their child still attended follow-up either regularly $(n=117,61.9 \%)$ or irregularly ( $n=24,12.7 \%$; Figure 1). Specialists most often seen for follow-up care were: pediatric oncologists $(n=111 / 141,78.7 \%)$, endocrinologists $(n=24 / 141,17.0 \%)$ and general practitioners ( $n=22 / 141,15.6 \%)$.

Among non-attenders, 11 (23\%) reported that they only ever see a doctor when a complication has occurred and 37 (77\%) reported that they had completed follow-up care. Among those seeing a doctor only for cancerassociated complications eight $(72.7 \%$ ) reported visiting a general practitioner and three (27.3\%) a pediatric oncologist. Parents of children who completed follow-up gave the following reasons: child was officially discharged $(n=33,89.2 \%)$, child thinks follow-up care is unimportant $(n=3,8.1 \%)$ and child does not want to visit a children's hospital (n=1, 2.7\%). Parental involvement in follow-up care

Most parents reported that they were involved in follow-up care ( $\mathrm{n}=130,92.2 \%$ of 141$)$.

Factors associated with non-attendance

We compared associations between not attending / attending follow-up and clinical, socio-demographic variables and parents' illness perception. In the univariable and Cox regression, non-attenders were older than attenders (OR 1.50, Confidence Interval (CI) 1.22-1.85p=0.001; Table 2) and diagnosed a longer time ago (OR 1.34, CI 1.16-1.55; $\mathrm{p}=0.001$; Figure 2). Regular visits were reported more frequently in younger age groups (Figure 1). Parents of nonattenders reported lower treatment control (they did not think that follow-up could help with late effects; IPQ item 4, OR 0.86, CI 0.79-0.96, $\mathrm{p}=0.005)$. In the multivariable regression older age at study (OR 1.32, CI 1.03-1.69, $\mathrm{p}=0.024)$, longer time since diagnosis (OR 1.20, CI 1.01-1.42, $\mathrm{p}=0.033$ ) and lower perceived treatment control (OR 0.86, CI 0.77-0.96, $\mathrm{p}=0.001$ ) remained associated with non-attendance.

Non-attenders who were officially discharged and nonattenders with other reasons were similar in sociodemographic characteristics and clinical factors. The only difference was that those who were officially discharged were more likely to be older $(p=0.040$; data not shown) and had parents with lower perceived treatment control $(\mathrm{p}=0.041)$. 
Factors associated with parental involvement

Parental involvement in follow-up care was associated with higher perceived treatment control (follow-up can help with late effects; IPQ item 4, OR 1.14, CI 1.021.27, $\mathrm{p}=0.020$; Table 3), increased identity (the child experiences symptoms as a consequence from the illness; IPQ item 5, OR 1.26, CI 1.06-1.49, p=0.008), increased concerns about the consequences of the illness (IPQ item 6, OR 1.17, CI 1.05-1.32, p=0.004) and increased emotions (emotionally more affected by consequences of the treatment; IPQ item 8, OR 1.17, CI 1.03-1.34, $\mathrm{p}=0.011$ ). Parental involvement was not significantly associated with socio-demographic and clinical characteristics. In the multivariable model only perceived treatment control remained associated (OR 1.13, CI 1.01-1.28, $\mathrm{p}=0.041$ ).

\section{DISCUSSION}

This is one of the first studies looking at follow-up attendance and parental involvement in young survivors of childhood cancer. We found that three out of four 11-17 year old survivors still attended followup care, however, the number decreased with age such that only half of the survivors aged 15 years or older still attended follow-up care. The specialists most often visited were pediatric oncologists followed by endocrinologists and general practitioners. As expected, attendance decreased with longer time since diagnosis and increasing age of survivor. The majority of parents reported that they were involved in followup care of their child. Parents of non-attenders reported lower treatment control (follow-up can help with late effects) whereas parents involved in follow-up were more likely to report greater treatment control.

Survivors diagnosed a longer time ago and who were older at the time of study were less likely to attend follow-up. This is in line with other studies which focused on young survivors [10] or on adolescent or adult survivors [7-9, 21, 22]. This can be hazardous because the likelihood of late effects and second malignancies increases with time since diagnosis [3]. Even 45 years after diagnosis survivors were at higher risk of premature death due to second cancers or severe cardiac or respiratory events [23]. Therefore lifelong follow-up care is often recommended [24]. However follow-up care in Switzerland is usually organized by pediatric oncologist and older survivors have to take over the responsibility for their follow-up care. They are more prone to get lost to follow-up when no regular follow-up at an adult specialist or general practitioner is organized. However, survivors in our sample were still in the age group in which follow-up at the pediatric oncologist is usually provided. Parents of non-attenders indicated lower treatment control indicating that they were probably unaware of the importance of follow-up care. These findings are in line with other studies showing that lack of knowledge might prevent survivors from seeking and receiving long-term medical or psychosocial follow-up care [7, 25-27]. To enhance care they suggested self-advocacy training for survivors and primary care physicians [26]. We showed in a previous study, including the same sample, that many parents had information needs especially on the domains follow-up care and late effects [28]. We assume that parents receiving the desired information would be more likely to understand the importance of follow-up care and motivate their child to stay in follow-up. A future study should investigate whether providing tailored additional information, preferably in written format, would increase attendance of young survivors. Results from the US showed that parents with a low perceived likelihood of their child developing late effects did not try to seek more information and were unlikely to attend follow-up [29]. We found no associations with any socio-demographic or clinical variables, which was in line with another study [13]. In contrast to other studies, which showed that follow-up attendance increased with severity of late effects [8], we found no difference by cancer diagnosis, parent-reported late effects or relapse even though risk-adapted follow-up care were indicated.

Among young children, parental involvement at medical visits is expected. In a recent study, mothers reported that the most important reason was concern for child's health and well-being. [12]. They also reported that it is a parental duty to accompany and support their child. This duty is of great importance in the younger age group where parents together with health care providers are responsible to motivate the child to stay in follow-up. In addition they help their child to become aware of their former disease and teach them the importance of early screening and detection of late effects. Parents were more likely to be involved if they thought follow-up care could help with late effects (treatment control) indicating that parents' understanding of the disease and being aware of the importance of follow-up led to greater involvement.

A qualitative study from England suggested that parental involvement is not only important for young survivors but also for older age groups; [30] other studies showed that parents remained involved in adult care because they remained concerned about cancer recurrence and overall health [13, 14]. Parental involvement was also reported to be very important in other chronic disease states. A study in children with diabetes showed that parental involvement was associated with improved maintenance and treatment adherence in disease management [31]. A different study in early obesity treatment showed that parental involvement was significantly higher in those who lost weight [32].

A limitation of this study is selection bias because parents of specific groups may have been more reluctant to complete the questionnaire; others may have been excluded because they did not complete the baseline questionnaire. Additionally, we only contacted one parent, mostly mothers, and thus information about involvement of the other parent is lacking. Also details about parental involvement in follow-up care were lacking. This also explains the large difference in numbers of male and female participants. Another 
limitation is self-reporting bias: parents might have forgotten the frequency of appointments or did not correctly recall the information and with the lack of medical record review we could not verify if children were officially discharged. The small sample size resulted in reduced accuracy for estimating effect sizes and therefore in large 95\% confidence intervals. Therefore, only limited stratification of results was possible and only a few variables could be included in the final multivariable models.

A major strength is the population-based sample of parents of childhood cancer survivors with prospectively collected data on the clinical variables of their children from the SCCR and data available from the follow-up questionnaire from the SCCSS. The response rate was good (67\%).

To improve follow-up attendance and parents' support of children, parents' beliefs should be strengthened through contact with other survivors and parents or health care professionals, emphasizing the importance of follow-up care. This might be especially important during and after transition to adult care. Researchers together with health care providers should organize regular meetings updating parents and survivors about potential late effects and give them the opportunity to meet and exchange their experiences. Each survivor and parents of young survivors should receive a personal passport for care and/or specific brochures detailing recommendations of ongoing screening. Such a passport was shown to be effective in survivors to improve knowledge of late effects and to see the benefits of long-term follow-up. [33-35]. Additionally, transition to adult care should be improved and more uniformly organized. Only if parents and survivors have the knowledge about effectiveness of follow-up care and are given adequate information throughout the cancer trajectory, will survivors reaching adulthood be able to take over responsibility of their own health and attend follow-up care visits independently even a long time after treatment has ended [7, 9, 36].

Longer duration since diagnosis is associated with lower follow-up attendance, and most parents who believed follow-up can help with late effects are involved in follow-up visits. Educating survivors and their parents on the importance and effectiveness of follow-up care might increase attendance in the longer term.

Conflict of Interest: The authors declare that they have no conflict of interest.

\section{References}

1. Taylor, N., et al., Need for psychological follow-up among young adult survivors of childhood cancer. Eur J Cancer Care (Engl), 2012. 21(1): p. 52-8.

2. Hudson, M.M., et al., Clinical ascertainment of health outcomes among adults treated for childhood cancer. JAMA, 2013. 309(22): p. 237181.

3. Oeffinger, K.C., et al., Chronic health conditions in adult survivors of childhood cancer. N Engl J Med, 2006. 355(15): p. 1572-82.

4. Scottish Intercollegiate Guidelines Network (SIGN). Long term follow-up of survivors of childhood cancer. A national clinical guideline, No. 76. 2004 [cited 201323 January]; Available from: http://www.sign.ac.uk/pdf/sign132.pdf.

5. Children's Oncology Group. Long-Term Follow-Up Guidelines for Survivors of Childhood, Adolescent, and Young Adult Cancers V3.0. 2008 [cited 2013 23 January]; Available from: http://www.survivorshipguidelines.org.

6. Wallace, W.H., et al., Long term follow-up of survivors of childhood cancer: summary of updated SIGN guidance. BMJ, 2013. 346: p. f1190.

7. Michel, G., et al., Can health beliefs help in explaining attendance to follow-up care? The Swiss Childhood Cancer Survivor Study. Psychooncology, 2011. 20(10): p. 1034-1043.

8. Rebholz, C.E., et al., Follow-up care amongst longterm childhood cancer survivors: a report from the Swiss Childhood Cancer Survivor Study. Eur J Cancer, 2011. 47(2): p. 221-9.

9. Lupatsch J, W.L., Rueegg CS, Teuffel MO, GumyPause F, Kuehni CE \& Michel G Follow-Up Care of Adolescent Cancer Survivors: The Role of Health-Beliefs. . Pediatric Blood and Cancer. accepted for publication.

10. Barakat, L.P., et al., Factors that contribute to posttreatment follow-up care for survivors of childhood cancer. J Cancer Surviv, 2012. 6(2): p. 155-162.

11. Dix, D.B., et al., Factors affecting the delivery of family-centered care in pediatric oncology. Pediatr Blood Cancer, 2009. 53(6): p. 1079-85.

12. Doshi, K., et al., Why mothers accompany adolescent and young adult childhood cancer survivors to follow-up clinic visits. J Pediatr Oncol Nurs, 2014. 31(1): p. 51-7.

13. Ressler, I.B., et al., Continued parental attendance at a clinic for adult survivors of childhood cancer. J Pediatr Hematol Oncol, 2003. 25(11): p. 868-73.

14. Kinahan, K.E., et al., Adult survivors of childhood cancer and their parents: experiences with survivorship and long-term follow-up. J Pediatr Hematol Oncol, 2008. 30(9): p. 651-8.

15. Michel, G., et al., The Swiss Childhood Cancer Registry: rationale, organisation and results for the years 2001-2005. Swiss Medical Weekly, 2007. 137(35-36): p. 502-509.

16. Michel, G., et al., Incidence of childhood cancer in Switzerland: The Swiss childhood cancer registry. Pediatr Blood Cancer, 2008. 50(1): p. 46-51.

17. Kuehni, C.E., et al., Cohort profile: The Swiss Childhood Cancer Survivor Study. Int J Epidemiol, 2012. 41(6): p. 1553-1564.

18. Kuehni, C.E., et al., Educational achievement in Swiss childhood cancer survivors compared with the general population. Cancer, 2012. 118(5): p. 1439-1449. 
Published in final edited form as: Support Care Cancer. 2016 Jul;24(7):3127-38. doi: 10.1007/s00520-016-3121-6

19. Broadbent, E., et al., The brief illness perception questionnaire. J Psychosom Res, 2006. 60(6): p. 631-7.

20. Steliarova-Foucher, E., et al., International Classification of Childhood Cancer, third edition. Cancer, 2005. 103(7): p. 1457-67.

21. Oeffinger, K.C., et al., Health care of young adult survivors of childhood cancer: a report from the Childhood Cancer Survivor Study. Ann Fam Med, 2004. 2(1): p. 61-70.

22. Shaw, A.K., et al., Use of health care services by survivors of childhood and adolescent cancer in Canada. Cancer, 2006. 106(8): p. 1829-37.

23. Reulen, R.C., et al., Long-term cause-specific mortality among survivors of childhood cancer. JAMA, 2010. 304(2): p. 172-9.

24. Haddy, R.I. and T.B. Haddy, Lifetime follow-up care after childhood cancer. J Am Board Fam Med, 2010. 23(5): p. 647-54.

25. Kadan-Lottick, N.S., et al., Childhood cancer survivors' knowledge about their past diagnosis and treatment: Childhood Cancer Survivor Study. JAMA, 2002. 287(14): p. 1832-1839.

26. Zebrack, B.J., et al., Health care for childhood cancer survivors: insights and perspectives from a Delphi panel of young adult survivors of childhood cancer. Cancer, 2004. 100(4): p. 843-50.

27. Aukema, E.J., et al., Explorative study on the aftercare of pediatric brain tumor survivors: a parents' perspective. Support Care Cancer, 2011. 19(10): p. 1637-46.

28. Vetsch J, R.C., Gianinazzi ME, Bergsträsser E, von der Weid NX, Michel G, Information needs in parents of long-term childhood cancer survivors. Pediatr Blood Cancer, 2015.

29. Cherven, B., et al., Knowledge and Risk Perception of Late Effects Among Childhood Cancer Survivors and Parents Before and After Visiting a Childhood Cancer Survivor Clinic. J Pediatr Oncol Nurs, 2014.

30. Earle, E.A., et al., Follow-up care for childhood cancer survivors: a focus group analysis. Eur J Cancer, 2005. 41(18): p. 2882-6.

31. King, P.S., et al., Longitudinal trajectories of parental involvement in Type 1 diabetes and adolescents' adherence. Health Psychol, 2014. 33(5): p. 424-32.

32. Heinberg, L.J., et al., Parent involvement is associated with early success in obesity treatment. Clin Pediatr (Phila), 2010. 49(5): p. 457-65.

33. Horowitz, M.E., et al., Passport for care: implementing the survivorship care plan. J Oncol Pract, 2009. 5(3): p. 110-2.

34. European Network for Cancer Research in Children and Adolescents. http://www.encca.eu/Pages/NewsItem.aspx?NewsI $\mathrm{D}=17,2013$.

35. Blaauwbroek, R., et al., Family doctor-driven follow-up for adult childhood cancer survivors supported by a web-based survivor care plan. J Cancer Surviv, 2012. 6(2): p. 163-71.

36. van Staa, A.L., et al., Crossing the transition chasm: experiences and recommendations for improving transitional care of young adults, parents and providers. Child Care Health Dev, 2011. 37(6): p. 821-32. 
Table 1. Characteristics of the study population, comparing participating parents and nonparticipating parents

\begin{tabular}{|c|c|c|c|c|}
\hline & \multicolumn{2}{|c|}{ Participating parents } & \multicolumn{2}{|c|}{ Non-participating parents } \\
\hline & $\mathbf{N}$ & $\%^{\mathrm{c}}$ & $\mathbf{N}$ & $\%^{c}$ \\
\hline Total & 189 & 100 & 117 & 100 \\
\hline \multicolumn{5}{|c|}{ Socio-demographic characteristics of parents } \\
\hline \multicolumn{5}{|c|}{ Sex } \\
\hline Female & 160 & 84.7 & n.a. ${ }^{d}$ & \\
\hline Male & 29 & 15.3 & n.a. & \\
\hline \multicolumn{5}{|l|}{ Migration background } \\
\hline Swiss & 173 & 91.5 & n.a. & \\
\hline Migration background & 16 & 8.5 & n.a. & \\
\hline \multicolumn{5}{|l|}{ Language region } \\
\hline German & 132 & 70.2 & 78 & 66.7 \\
\hline French & 56 & 29.8 & 39 & 33.3 \\
\hline \multicolumn{5}{|l|}{ Education } \\
\hline Primary & 101 & 54.3 & n.a. & \\
\hline Secondary & 62 & 33.3 & n.a. & \\
\hline Tertiary & 23 & 12.4 & n.a. & \\
\hline \multicolumn{5}{|l|}{ Employment } \\
\hline Employed & 150 & 79.4 & n.a. & \\
\hline Unemployed & 39 & 20.6 & n.a. & \\
\hline \multicolumn{5}{|c|}{ Clinical characteristics of the child } \\
\hline \multicolumn{5}{|c|}{ Diagnosis } \\
\hline Leukemias & 74 & 39.2 & 46 & 39.3 \\
\hline Lymphomas & 16 & 8.5 & 10 & 8.5 \\
\hline CNS tumors & 34 & 18.0 & 23 & 19.7 \\
\hline Neuroblastoma & 13 & 6.9 & 8 & 6.8 \\
\hline Retinoblastoma & 13 & 6.9 & 5 & 4.3 \\
\hline Renal tumors & 12 & 6.3 & 8 & 6.8 \\
\hline Hepatic tumors & 4 & 2.1 & 3 & 2.6 \\
\hline Malignant tumors & 2 & 1.1 & 3 & 2.6 \\
\hline Soft tissue sarcomas & 14 & 7.4 & 3 & 2.6 \\
\hline Germ cell tumors & 2 & 1.1 & 3 & 2.6 \\
\hline $\mathrm{LCH}$ & 2 & 1.1 & 3 & 2.6 \\
\hline Other ${ }^{\mathrm{e}}$ & 3 & 1.6 & 0 & 0.0 \\
\hline \multicolumn{5}{|l|}{ Treatment received ${ }^{f}$} \\
\hline Surgery only & 30 & 16.0 & 20 & 17.5 \\
\hline Chemotherapy & 118 & 63.1 & 74 & 64.9 \\
\hline Radiotherapy & 30 & 16.0 & 17 & 14.9 \\
\hline SCT & 9 & 4.9 & 3 & 2.6 \\
\hline \multicolumn{5}{|l|}{ Type of treating hospital } \\
\hline University hospital & 160 & 84.7 & 102 & 87.2 \\
\hline Regional hospital & 29 & 15.3 & 15 & 12.8 \\
\hline
\end{tabular}


Published in final edited form as: Support Care Cancer. 2016 Jul;24(7):3127-38. doi: 10.1007/s00520-016-3121-6

Table 1 contd.

\begin{tabular}{|c|c|c|c|c|}
\hline & \multicolumn{2}{|c|}{ Participating parents } & \multicolumn{2}{|c|}{ Non-participating parents ${ }^{\mathrm{a}}$} \\
\hline & $\mathbf{N}$ & $\%^{c}$ & $\mathbf{N}$ & $\%^{c}$ \\
\hline Total & 189 & 100 & 117 & 100 \\
\hline \multicolumn{5}{|l|}{ Relapse } \\
\hline No & 168 & 88.9 & 104 & 88.9 \\
\hline Yes & 21 & 11.1 & 13 & 11.1 \\
\hline \multicolumn{5}{|c|}{ Parent-reported late effects } \\
\hline No & 100 & 54.4 & 68 & 64.2 \\
\hline \multirow[t]{3}{*}{ Yes } & 84 & 45.6 & 38 & 35.8 \\
\hline & \multicolumn{2}{|c|}{ Participants } & \multicolumn{2}{|c|}{ Non-participants ${ }^{\mathrm{a}}$} \\
\hline & Mean & SD & Mean & SD \\
\hline Parent's age & 46.1 & 4.8 & n.a. & n.a. \\
\hline Child's age at study & 14.7 & 1.8 & 15.0 & 1.9 \\
\hline Child's age at diagnosis & 3.4 & 2.2 & 3.6 & 2.4 \\
\hline Time since diagnosis & 11.3 & 2.5 & 11.4 & 2.5 \\
\hline IPQ1: Consequences & 3.1 & 2.9 & n.a. & n.a. \\
\hline IPQ2: Timeline & 5.2 & 4.1 & n.a. & n.a. \\
\hline IPQ3: Personal control & 3.5 & 2.9 & n.a. & n.a. \\
\hline IPQ4: Treatment control & 6.6 & 3.4 & n.a. & n.a. \\
\hline IPQ5: Identity & 2.4 & 2.9 & n.a. & n.a. \\
\hline IPQ6: Concern & 5.4 & 3.3 & n.a. & n.a. \\
\hline $\begin{array}{l}\text { IPQ7: Illness } \\
\text { comprehensibility }\end{array}$ & 7.6 & 2.6 & n.a. & n.a. \\
\hline IPQ8: Emotions & 5.0 & 3.0 & n.a. & n.a. \\
\hline
\end{tabular}

Note Percentages are based upon available data for each variable. Abbreviations: CNS, Central Nervous System; LCH, Langerhans Cell Histiocytosis; SCT, Stem Cell Transplantation; SD, Standard Deviation; IPQ, Illness

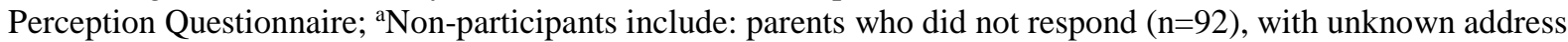
$(n=22)$ or who refused to participate $(n=3)$ (Supplemental Figure 2); ${ }^{c}$ Column percentages are given; ${ }^{\text {information was }}$

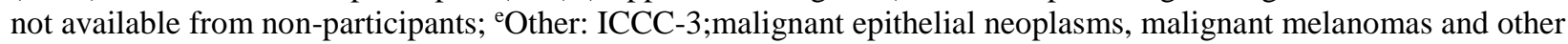
or unspecified malignant neoplasms; ${ }^{\mathrm{f}}$ Chemotherapy may include surgery, radiotherapy may include chemotherapy and/or surgery. 
Published in final edited form as: Support Care Cancer. 2016 Jul;24(7):3127-38. doi: 10.1007/s00520-016-3121-6

Table 2. Factors associated with follow-up non-attendance (from univariable and multivariable logistic regression models)

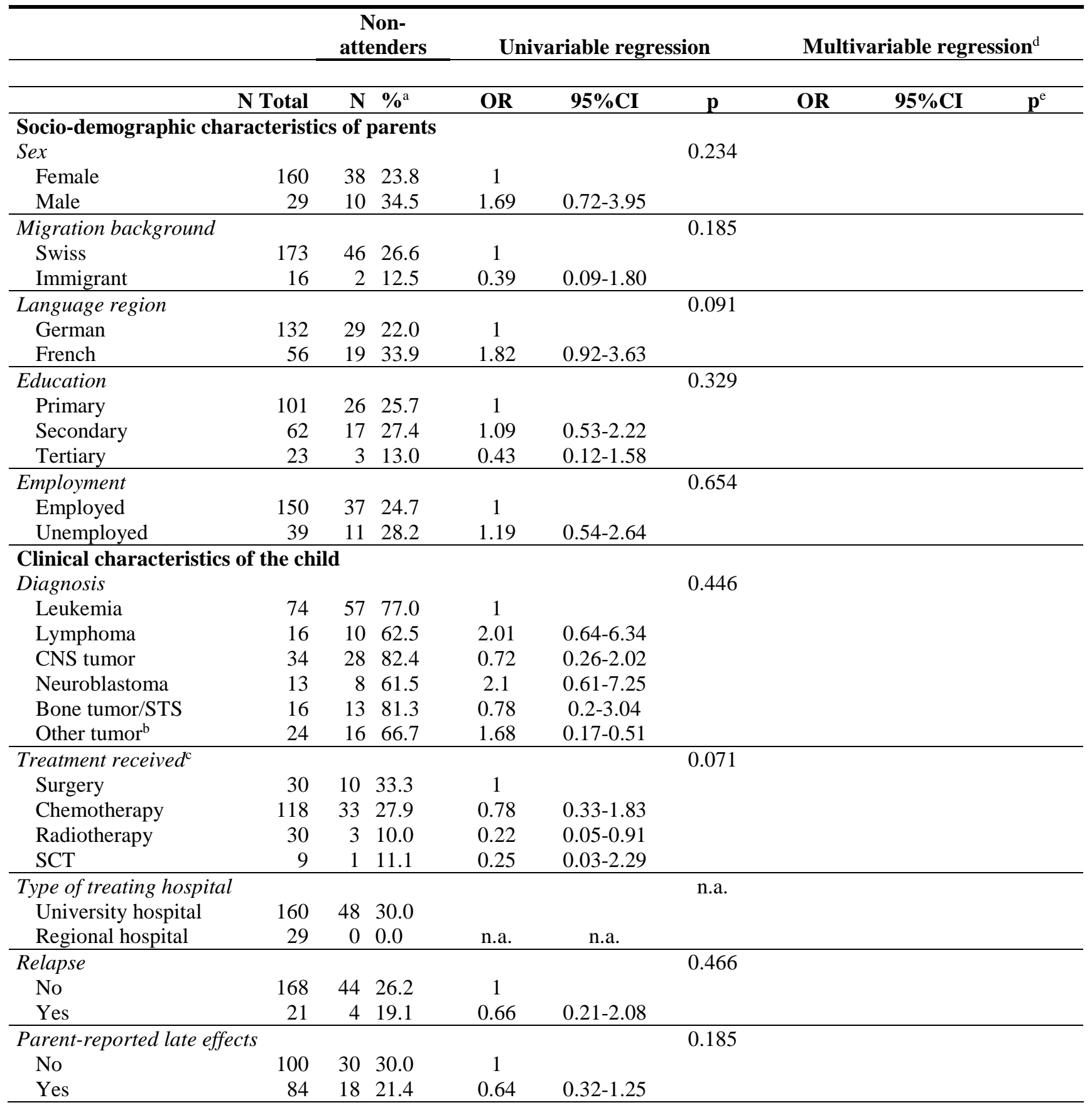


Published in final edited form as: Support Care Cancer. 2016 Jul;24(7):3127-38. doi: 10.1007/s00520-016-3121-6

Table 2 contd.

\begin{tabular}{|c|c|c|c|c|c|c|c|c|c|}
\hline & \multicolumn{3}{|c|}{$\begin{array}{c}\text { Non- } \\
\text { attenders }\end{array}$} & \multicolumn{3}{|c|}{ Univariable regression } & \multicolumn{3}{|c|}{ Multivariable regression $^{\mathrm{d}}$} \\
\hline & N Total & Mean & SD & OR & $95 \%$ CI & $\mathbf{p}$ & OR & $95 \% \mathrm{CI}$ & $\mathbf{p}^{\mathrm{e}}$ \\
\hline Age at study (years) & 181 & 46.79 & 5.16 & 1.04 & $0.97-1.20$ & 0.240 & & & \\
\hline $\begin{array}{l}\text { Child's age at study } \\
\text { (years) }\end{array}$ & 189 & 15.72 & 1.71 & 1.50 & $1.22-1.85$ & 0.001 & 1.32 & $1.03-1.69$ & 0.024 \\
\hline $\begin{array}{l}\text { Time since diagnosis } \\
\text { (years) }\end{array}$ & 189 & 12.57 & 2.22 & 1.34 & $1.16-1.55$ & 0.001 & 1.20 & $1.01-1.42$ & 0.033 \\
\hline IPQ1: Consequences & 185 & 3.05 & 2.95 & 0.96 & $0.86-1.08$ & 0.551 & & & \\
\hline IPQ2: Timeline & 182 & 5.21 & 4.13 & 0.97 & $0.89-1.06$ & 0.573 & & & \\
\hline IPQ3: Personal control & 177 & 3.50 & 2.89 & 0.99 & $0.88-1.12$ & 0.885 & & & \\
\hline IPQ4: Treatment control & 182 & 6.64 & 3.40 & 0.86 & $0.79-0.96$ & 0.005 & 0.86 & $0.77-0.96$ & 0.001 \\
\hline IPQ5: Identity & 183 & 2.44 & 2.87 & 0.88 & $0.78-1.02$ & 0.063 & & & \\
\hline IPQ6: Concern & 187 & 5.35 & 3.34 & 0.96 & $0.87-1.05$ & 0.368 & & & \\
\hline IPQ7: Illness & & & & & & & & & \\
\hline comprehensibility & 184 & 7.58 & 3.05 & 0.92 & $0.81-1.04$ & 0.198 & & & \\
\hline IPQ8: Emotions & 183 & 5.02 & 3.05 & 0.95 & $0.86-1.07$ & 0.465 & & & \\
\hline
\end{tabular}

Note Percentages are based upon available data for each variable. Abbreviations: CI, Confidence Interval; CNS, Central Nervous System; OR, Odds Ratio; SCT, Stem Cell Transplantation; ${ }^{a}$ Row percentages are given; ${ }^{b}$ Other: malignant epithelial neoplasms, malignant melanomas and other or unspecified malignant neoplasms; ${ }^{\mathrm{c}} \mathrm{Chemotherapy}$ may include surgery, radiotherapy may include chemotherapy and/or surgery; ${ }^{\mathrm{d}}$ All variables that were statistically significant in the univariable model on a significance level of $\mathrm{p}<0.05$ were included; ${ }^{\mathrm{e}} \mathrm{p}$-value calculated with likelihood ratio test. 
Published in final edited form as: Support Care Cancer. 2016 Jul;24(7):3127-38. doi: 10.1007/s00520-016-3121-6

Table 3. Factors associated with parental involvement in follow-up care (from univariable and multivariable logistic regression models)

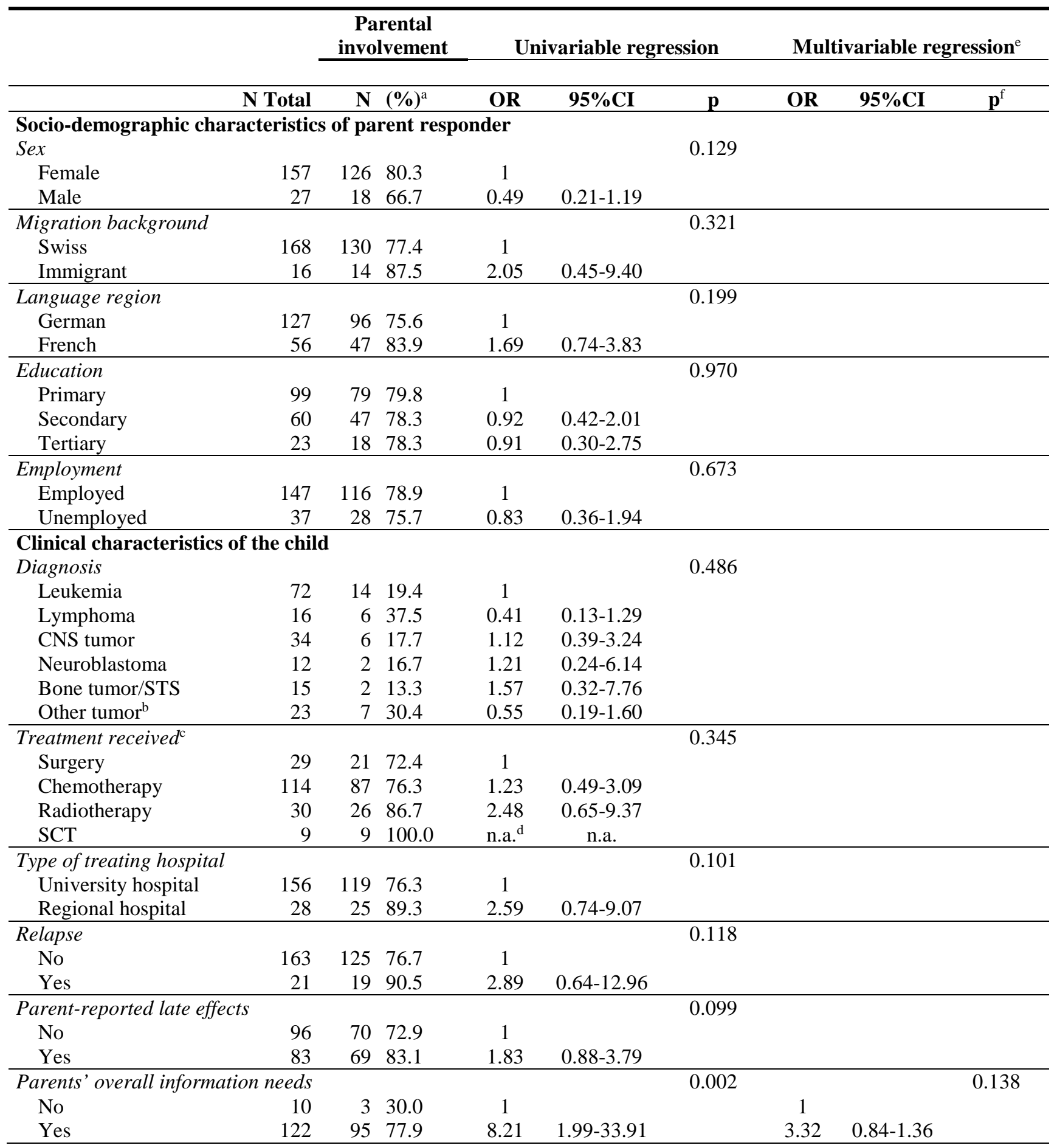

Table 3 contd. 


\begin{tabular}{|c|c|c|c|c|c|c|c|c|c|}
\hline & & & & \multicolumn{3}{|c|}{ Univariable regression } & \multicolumn{3}{|c|}{ Multivariable regression } \\
\hline & N Total & Mean & SD & OR & $95 \% \mathrm{CI}$ & $\mathbf{p}$ & OR & $95 \% \mathrm{CI}$ & $\mathbf{p}^{\mathrm{f}}$ \\
\hline Age at study (years) & 181 & 45.77 & 4.57 & 0.99 & $0.86-1.15$ & 0.896 & & & \\
\hline $\begin{array}{l}\text { Child's age at study } \\
\text { (years) }\end{array}$ & 189 & 14.51 & 1.77 & 1.06 & $0.73-1.52$ & 0.760 & & & \\
\hline $\begin{array}{l}\text { Time since diagnosis } \\
\text { (years) }\end{array}$ & 189 & 10.91 & 2.46 & 1.17 & $0.88-1.57$ & 0.266 & & & \\
\hline IPQ1: Consequences & 185 & 3.05 & 2.95 & 1.11 & $0.97-1.26$ & 0.112 & & & \\
\hline IPQ2: Timeline & 182 & 5.21 & 4.13 & 1.06 & $0.97-1.17$ & 0.156 & & & \\
\hline IPQ3: Personal control & 184 & 3.49 & 2.89 & 1.06 & $0.93-1.22$ & 0.382 & & & \\
\hline IPQ4: Treatment control & 182 & 6.63 & 3.35 & 1.14 & $1.02-1.27$ & 0.020 & 1.07 & $0.84-1.36$ & 0.577 \\
\hline IPQ5: Identity & 183 & 2.43 & 2.86 & 1.26 & $1.06-1.49$ & 0.008 & 1.54 & $0.83-2.87$ & 0.093 \\
\hline IPQ6: Concern & 187 & 5.35 & 3.34 & 1.17 & $1.05-1.32$ & 0.004 & 1.15 & $0.85-1.57$ & 0.354 \\
\hline $\begin{array}{l}\text { IPQ7: Illness } \\
\text { comprehensibility }\end{array}$ & 184 & 7.58 & 2.57 & 1.04 & 0.91-1.19 & 0.547 & & & \\
\hline IPQ8: Emotions & 183 & 5.02 & 3.04 & 1.17 & $1.03-1.34$ & 0.011 & 1.00 & $0.70-1.40$ & 0.960 \\
\hline
\end{tabular}

Note Percentages are based upon available data for each variable. Abbreviations: CI, Confidence Interval; CNS,

Central Nervous System; OR, Odds ratio; SCT, Stem Cell Transplantation; ${ }^{a}$ Row percentages are given; ${ }^{\text {bOther: }}$

malignant epithelial neoplasms, malignant melanomas and other or unspecified malignant neoplasms; ${ }^{\mathrm{c}}$ Chemotherapy may include surgery, radiotherapy may include chemotherapy and/or surgery; ${ }^{\mathrm{d}}$ success perfectly predicted; ${ }^{\mathrm{e}} \mathrm{All}$ variables that were statistically significant in the univariable model on a significance level of $\mathrm{p}<0.05$ were included; ${ }_{\mathrm{f}}^{\mathrm{p}}$-value calculated with likelihood ratio test. 
Figure 1. Follow-up attendance of young childhood cancer survivors

Figure 1 shows the overall proportion of childhood cancer survivors attending and not attending follow-up care stratified by child's age at study

Legend: Regular visit: 1) 'yes, my child still attends regular follow-up appointments'; Irregular visit: 2) 'yes, my child still has irregular follow-up appointments'; Seeing a doctor when experiencing complications: 3) 'no, regular follow-up is completed, but my child goes to the treating doctor when having cancer-associated complications; discharged: 4) 'no, regular followup is completed and my child has not seen the treating doctor for a while'

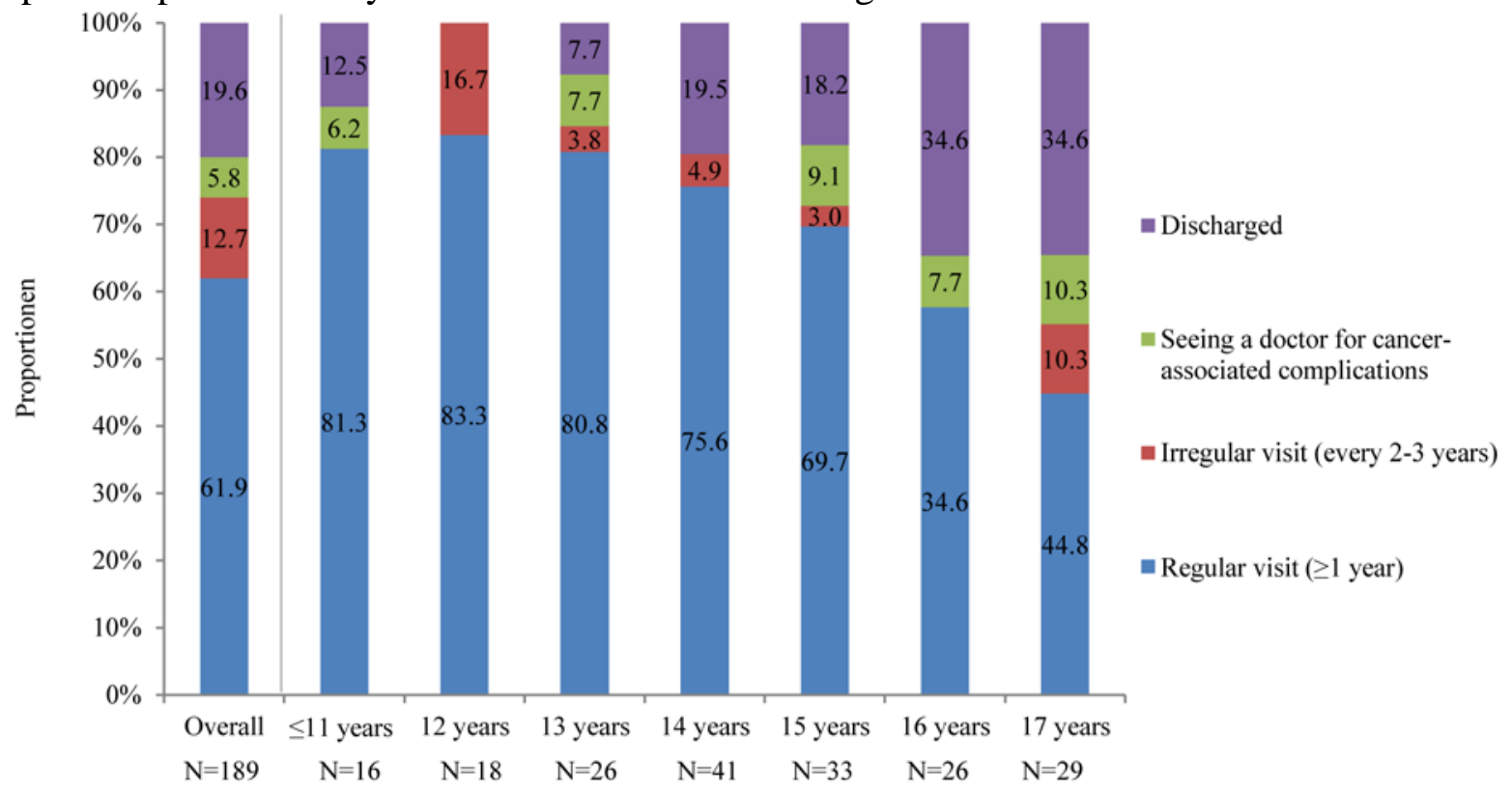


Published in final edited form as: Support Care Cancer. 2016 Jul;24(7):3127-38. doi: 10.1007/s00520-016-3121-6

Figure 2. Follow-up attendance calculated from Kaplan-Meier estimation stratified by child's age at diagnosis

Figure 2 shows the probability of follow-up attendance over time since diagnosis (years) stratified by the child's age at diagnosis: $0-1$ years, $2-4$ years, $5+$ years

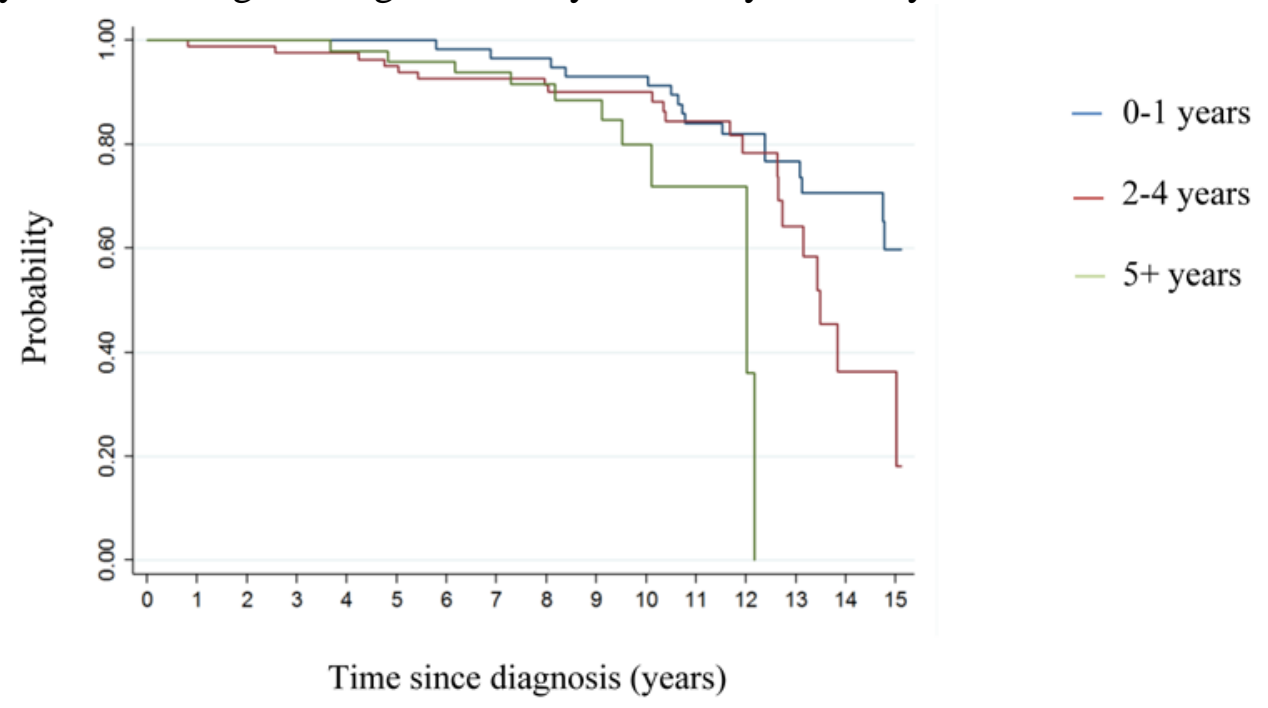


Published in final edited form as: Support Care Cancer. 2016 Jul;24(7):3127-38. doi: 10.1007/s00520-016-3121-6

Supplemental Figure 1: Different data sources of the variables used in the present study Supplemental figure 1 shows the data sources and the variables used in the present study

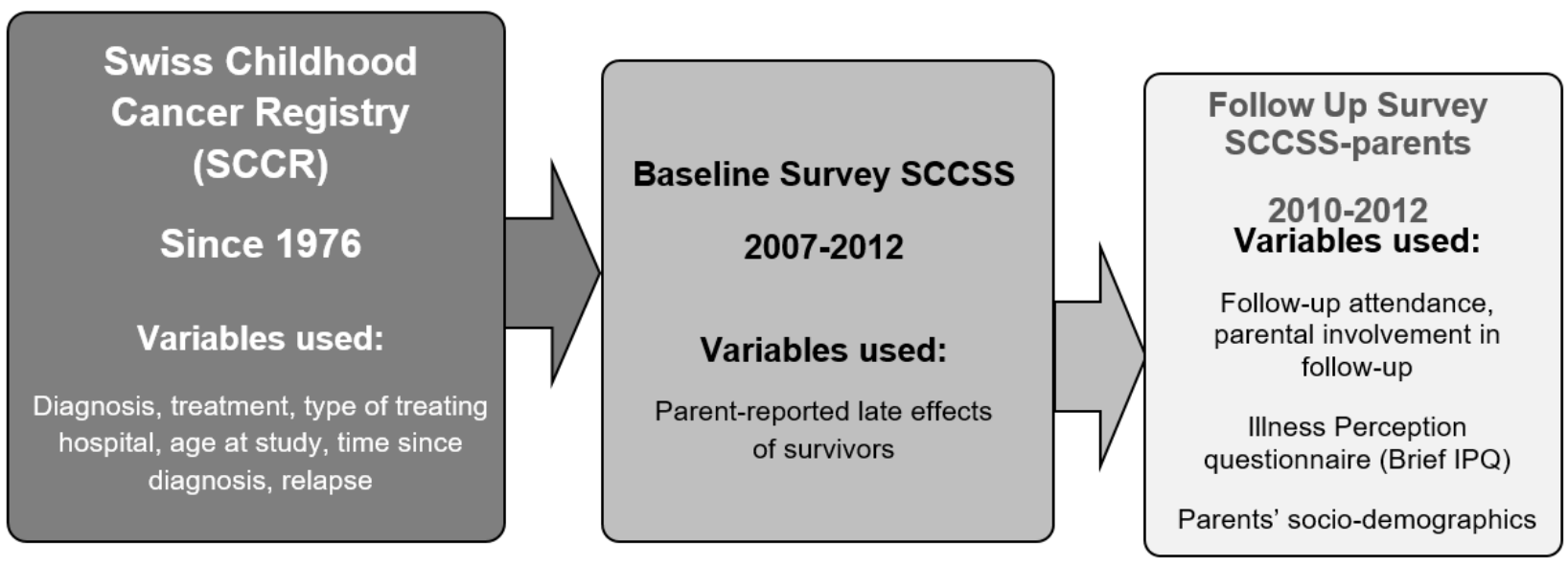

Supplemental Figure 2: Participants and response rate of parents in the Swiss Childhood Cancer Survivor Study follow-up questionnaire

Supplemental figure 2 shows the flow diagram of our study population starting from those parents eligible for the study to those included in the analysis.

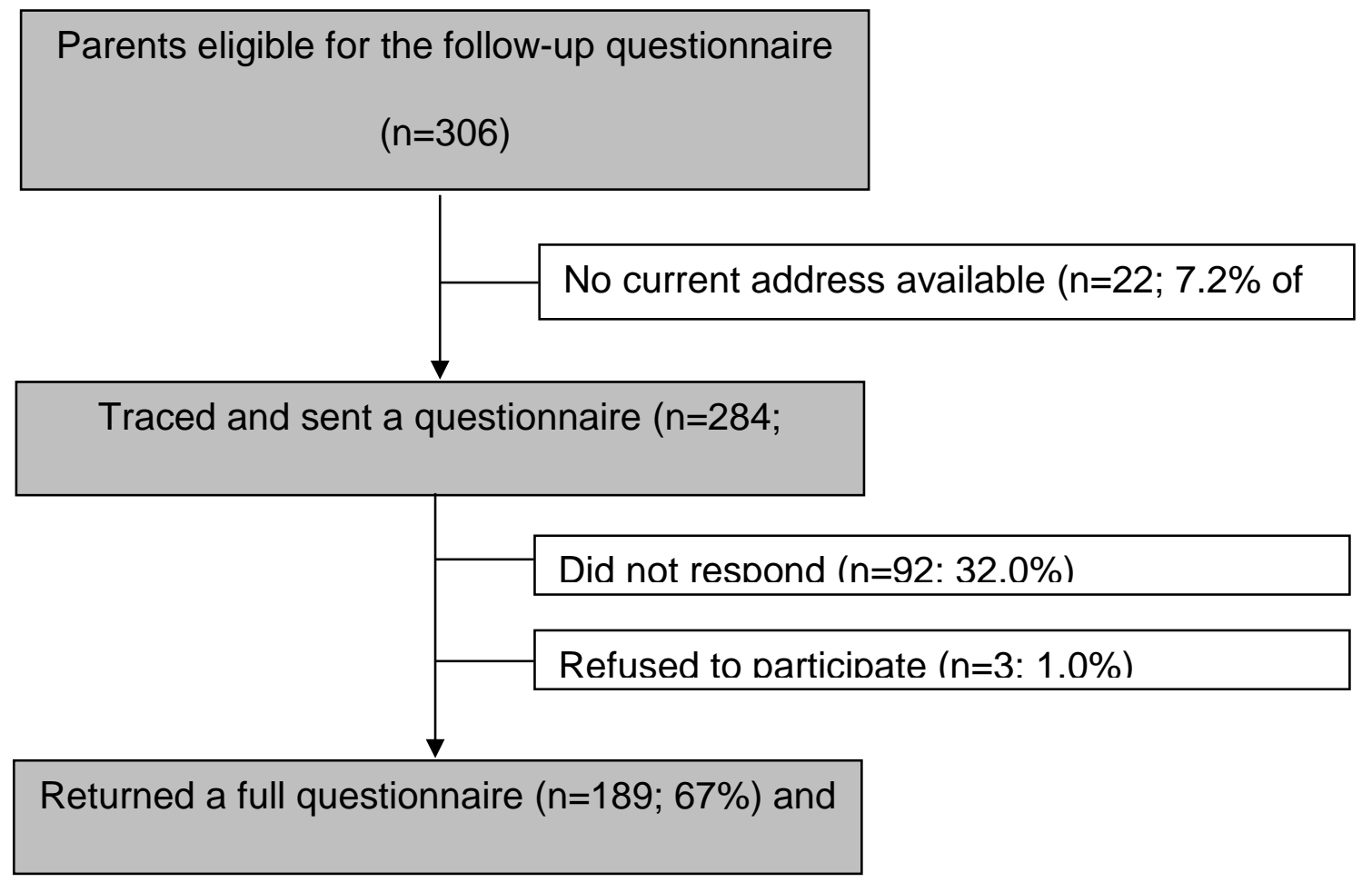

